\title{
Desafios na organização de parcerias público-privadas em saúde no Brasil. Análise de projetos estruturados entre janeiro de 2010 e março de 2014
}

\author{
Antonio Pires Barbosa \\ Universidade Nove de Julho / Programa de Pós-Graduação em Administração \\ São Paulo / SP - Brasil \\ Ana Maria Malik \\ Fundação Getulio Vargas / Escola de Administração de Empresas de São Paulo, \\ Departamento de Administração e Recursos Humanos \\ São Paulo / SP - Brasil
}

\begin{abstract}
A saúde é um dos setores de serviços que sofrem intensa pressão de demanda. As estruturas disponíveis no SUS e sua insuficiente capacidade de investimento têm comprometido a atenção prestada. A estruturação de PPP apresenta-se como abordagem alternativa para reduzir déficit de serviços. O estudo, baseado em metodologia analítica com o uso da tríade tese-antítese-síntese, observou a implantação de 24 PPP no Brasil com a análise de seus perfis, fatores críticos, limitações e tendências, levando em consideração a observância dos critérios técnicos dos processos, a existência de estudos epidemiológicos que os justificassem, o cumprimento das etapas legais e a participação do setor saúde e instâncias jurídicas. Conclui-se que existem quatro grupos de projetos com diferentes características de implantação e sugerem-se medidas de solução das situações que garantam a isonomia contratual.
\end{abstract}

Palavras-chave: gestão em saúde; políticas de saúde; planejamento em saúde; administração financeira de hospitais; PPP em hospitais.

Desafíos en la organización de asociaciones público-privadas en materia de salud en Brasil. Análisis de proyectos constituidos entre enero de 2010 y marzo de 2014

La salud es uno de los sectores de servicios que sufren una fuerte presión de la demanda. Las estructuras disponibles en el SNS y su insuficiente capacidad de inversión han comprometido la atención recibida. La estructuración de las APP se presenta como un enfoque alternativo para reducir el déficit em los servicios. El estudio, basado en la metodología analítica utilizando la tesis-antítesis-síntesis tríada, observó la aplicación de 24 APP en Brasil con el análisis de sus perfiles, los factores críticos, limitaciones

DOI: http://dx.doi.org/10.1590/0034-7612136177

Artigo recebido em 10 jun. 2014 e aceito em 5 mar. 2015. 
y tendencias. Se concluye que hay 4 grupos de proyectos con diferentes modelos de aplicación y las medidas que sugieren soluciones a las situaciones que aseguren la igualdad contractual.

Palabras clave: gestión de la salud; políticas de salud; planificación de la salud, administração financiera de hospitales; APP en organizaciones hospitalarias.

Challenges in the organization of health public-private partnerships in Brazil. Analysis of projects designed between January 2010 and March 2014.

Health Care is one of the service sectors that suffers intense demand pressure. The structures available in Brazilian Health Unified System (SUS) and its insufficient investment capacity have compromised the care provided. The structuring of PPP is presented as an alternative approach to reduce the service deficit. The study, based on analytical methodology using the triad thesis-antithesis-synthesis, observed the implementation of 24 PPP in Brazilian hospitals with analysis of their profiles, critical factors, limitations and trends. It was taken into consideration the observation of the processes' technical criteria, the existence of epidemiological studies that justified them, the accomplishment of legal steps and the participation of the health sector and legal bodies. In conclusion, there are 4 groups of projects with different implementation characteristics and solution measures are suggested to the situations that ensure contractual equality.

KeYwords: health management; health policies; health planning; hospital financial management; PPP in hospitals' organizations.

\section{Introdução}

A evolução demográfica da população brasileira nos últimos 40 anos apresentou sensíveis alterações, expressas em perfis etários e indicadores básicos. A sociedade evoluiu de um contingente com predomínio de jovens para uma distribuição demográfica similar à de países desenvolvidos. As taxas de fecundidade total reduziram-se de 5,76 na década de 1970 para 1,87 em 2010. As taxas de mortalidade infantil, por sua vez, decresceram de 30/1.000 nascidos vivos nos anos 1990 para uma projeção de 15 em 2013 e de 7,1 em 2030 (IBGE, 2014). A expectativa de vida ao nascer também passa por alterações decorrentes das mudanças econômicas e sociais que perpassam a sociedade, atingindo índices de 70 anos em 2000 e 74 anos em 2010. O Produto Interno Bruto (PIB) nominal do país, sem considerar a inflação acumulada do período, cresceu mais de 200\% entre 2000 e 2010 (IBGE, 2014).

Essas transformações estão na raiz da mudança de perfil epidemiológico por que passa a sociedade na atualidade. O envelhecimento populacional, a urbanização acelerada, a mudança dos padrões de consumo com a incorporação de um grande contingente aos mercados de bens, serviços e trabalho têm aumentado a frequência de doenças crônico-degenerativas e das condições de agravos agudos relacionados às causas externas (Medici, 2011). Contudo, o modelo assistencial disponível para conter essas demandas não tem acompanhado o movimento da sociedade em busca de ganhos de eficiência. Por exemplo, o Conselho Federal de Medicina (CFM) estima uma redução anual média de cerca de 4 mil leitos hospitalares no país na última década (Portal CFM, 2014). 
A relação de leitos/1.000 hab. decresceu de 2,47 para 2,35 no país entre 2007 e 2012, com uma redução maior sobre o componente destinado ao atendimento do SUS. Considerando-se o volume de leitos dedicados ao SUS sem os leitos complementares, o setor privado disponibilizava cerca de 160 mil unidades, correspondentes a 50,1\% do total. Os leitos públicos (pertencentes ao Estado) significaram 49,9\%, dos quais 8,1\% eram administrados pelo nível federal, 41,3\% pelos estados e 50,6\% pelos municípios (Brasil, 2012).

Em paralelo assistiu-se, nas décadas de 1980 e 1990, à redução da capacidade de investimentos dos países da América Latina em função dos ajustes e crises econômicas que assolaram a região. No Brasil, nesse período, ocorreu uma queda do investimento público de cerca de $3,1 \%$ do PIB para 0,8\% nos anos 2000. A alternativa à redução do estoque de investimentos do Estado foi a busca de participação privada em projetos de infraestrutura (Grilo, 2008).

A participação privada, numa primeira etapa, posterior à estabilização econômica, efetivou-se com a privatização nas áreas de energia, telefonia e transportes, com as justificativas da busca de eficiência e melhoria da competitividade, geração de receitas e melhoria da qualidade dos serviços. Esse ciclo se esgotou no início dos anos 2000 com a redução do número de empresas privatizáveis e com a queda no interesse privado no processo.

Com a Lei no 11.079 (Brasil, 2004), constituiu-se um novo regime de contratação de serviços por meio de parcerias do setor público com a iniciativa privada em setores de infraestrutura, iniciando-se um processo de rediscussão dos papéis do Estado, sociedade e iniciativa privada na provisão de serviços e investimentos. Diferentemente das concessões tradicionais, em que os parceiros privados auferem suas receitas por meio da cobrança por serviços e produtos, a legislação de 2004 define parceria público-privada (PPP) a partir de novos parâmetros de contratação, alocação de responsabilidades e compartilhamento de riscos, superando limitações regulatórias dos contratos entre governo e iniciativa privada. Entre as premissas importantes que a caracterizam estão a utilização de referenciais técnicos de mensuração de necessidades; a contratação por longos períodos e a instituição de mecanismos de garantia financeira que tragam estabilidade à relação contratual. Entre as diretrizes principais que regem o modelo, estabelecidas no art. 4 da lei, estão o compartilhamento de riscos e benefícios, o respeito aos interesses de usuários, a sustentabilidade fiscal, a indelegabilidade das funções primárias de Estado e a transparência de procedimentos e decisões (Brasil, 2004; Carrera, 2014).

Na prática, em virtude da insuficiente capacidade do Estado em investir em infraestrutura, iniciou-se um ciclo de proposições de PPP envolvendo diversos setores econômicos. Por exemplo, entre 2005 e 2010 foram iniciados 36 procedimentos com vistas à implantação de PPP nos níveis federal e estaduais em áreas como estradas, irrigação, centrais de atendimento público, estádios esportivos, saneamento básico e centros logísticos. Durante esse período, a única experiência de implantação de PPP em saúde ocorreu em 2010, com a implantação do Hospital do Subúrbio em Salvador (Carrera, 2012). Na verdade, a despeito do manifesto interesse da iniciativa privada em investir no setor, até março de 2014 apenas tinham sido contratadas, além da implantação do Hospital do Subúrbio, a construção do Hospital do Barreiro (Belo Horizonte), a implantação das redes de atenção básica de Belo Horizonte e Manaus, e 
a instalação da fábrica de medicamentos da Fundação para o Remédio Popular (São Paulo) (PPPBrasil, 2014). Considerando a capacidade de investimentos e atualizações existente no setor público e as possibilidades inerentes ao novo modelo, causam estranheza as dificuldades com que os atores envolvidos se defrontam para a consecução de contratos efetivos.

A pergunta que este artigo se propõe responder é: por quais razões o processo de contratação de PPP em saúde tem apresentado dificuldades em sua implantação e contratação? Subsidiariamente o estudo busca compreender os modelos de estruturação das PPPs em saúde, quais os papéis e os interesses dos atores envolvidos, que oportunidades se apresentam e quais as possíveis soluções para os problemas detectados.

\section{Referencial teórico}

O sistema de saúde no Brasil, a partir da Constituição Federal (CF) de 1988, estruturou-se sob os signos da busca da equidade, da universalização do atendimento, da descentralização política e operacional e do financiamento tripartite (Brasil, 1988). Além disso, a CF também estabeleceu que a saúde é campo de atuação econômica livre à iniciativa privada, cabendo a esta atuar de maneira complementar às estruturas públicas. Estas definições constitucionais foram regulamentadas no ano de 1990, por intermédio das Leis no 8.080 (Brasil, 1990a), com as atribuições, competências e responsabilidades dos níveis componentes do SUS, e no 8.142 (Brasil, 1990b), que dispõe sobre participação social e transferências de recursos intergovernamentais no sistema. No setor privado de assistência médico-hospitalar, a criação da Agência Nacional de Saúde Suplementar (ANS) serviu para organizar e regular as relações contratuais com o setor privado.

Desde suas origens, o sistema passou por vários períodos de revisão operacional em consequência da insuficiência de recursos para custeio e investimentos. O gasto per capita em saúde variou, entre 2000 e 2009 , de $\mathrm{R} \$ 558$ a $\mathrm{R} \$ 1.442$, tendo as famílias se responsabilizado por 60\% destes recursos (Barbosa, 2013). Levantamentos realizados pela Consultoria de Orçamento e Fiscalização Financeira da Câmara dos Deputados (Brasil, 2011) sobre o período 2000-11 revelam que a participação dos entes da Federação tem apresentado sensíveis alterações no período, conforme demonstra o gráfico 1. Por exemplo, a participação da União no gasto em saúde caiu de 58,6\% em 2000 para 43,4\% em 2008, atingindo 45,4\% em 2011, ao passo que a participação dos demais entes federados aumentou, sobretudo dos municípios, que se elevou de $21,2 \%$ para $28,8 \%$.

A partir de 2006, com o Pacto pela Saúde (Brasil, 2006), o SUS passa a privilegiar ações sobre a atenção básica, com concentração na estratégia de saúde da família, promovendo uma revisão dos mecanismos de repasses federais, implantando os blocos de atenção, os quais se constituíram nos mecanismos de financiamento da assistência com maior descentralização administrativa. Compõem os blocos as ações destinadas à atenção básica, à assistência de média e alta complexidade, à assistência farmacêutica, às vigilâncias sanitária e epidemiológica e ao apoio à gestão do SUS. A fase se caracterizou pela valorização de políticas públicas de 
prevenção, promoção e gerenciamento de condições de saúde das populações adscritas aos programas de atenção primária.

Gráfico 1

Distribuição percentual de despesas com ações e serviços públicos de saúde

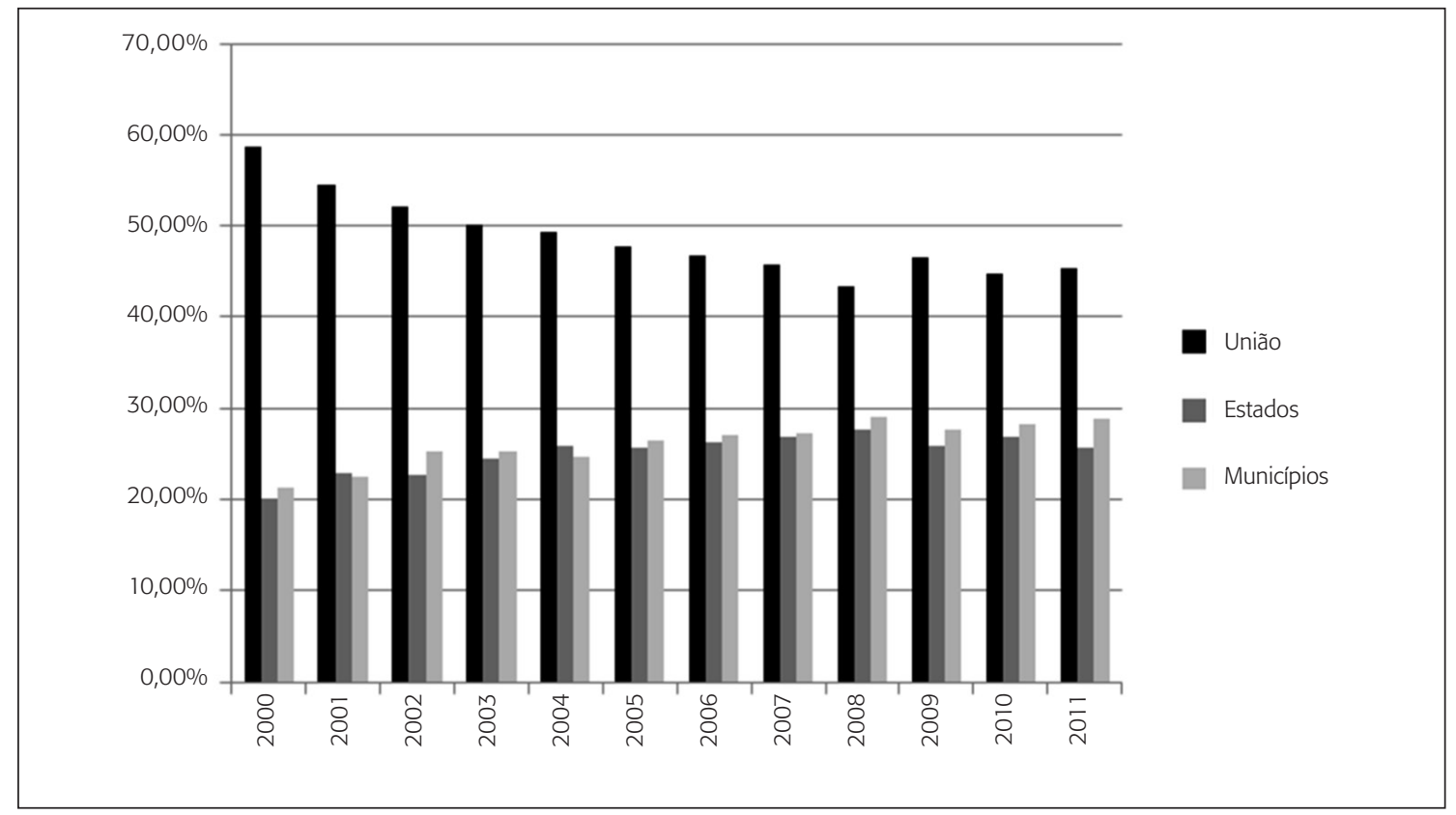

Fonte: Consultoria de Orçamento e Finanças - Câmara dos Deputados - 2011. Elaborado pelos autores.

Em 2011, com o desenvolvimento das redes de assistência, o Ministério da Saúde (MS) instituiu novos mecanismos de administração de recursos baseados na operação conjunta de estruturas assistenciais interligadas por sistemas de regulação e comunicação centralizados. Nessa etapa, os repasses federais passaram a privilegiar a assistência por meio de linhas de cuidados e protocolos assistenciais (Mendes, 2011). São implantadas as redes de urgência e emergência, cegonha, rede de atenção à saúde de pessoas com doenças crônicas, de atenção psicossocial e a de portadores de necessidades especiais.

Entretanto, no período anterior às redes, os recursos orçamentários destinados à modernização do parque assistencial no Brasil situaram-se num percentual de 1,3\% do total repassado pelo MS às demais instâncias do SUS. Especificamente com relação à modernização da rede de hospitais vinculados ao SUS podem ser relacionadas como possíveis causas para este fenômeno tanto ações propositivas, como a redução da necessidade de internações com a incorporação de tecnologias de média e alta complexidade ambulatoriais, quanto dificuldades como movimentos de redução de oferta de leitos aparentemente decorrentes do subfinanciamento do sistema. Em consequência, o ônus de investimentos na rede hospitalar pública para 
atendimento de média e alta complexidade acaba por recair sobre os estados e municípios, que nem sempre dispõem de capacidade orçamentária suficiente para sua realização, em função dos limites da lei de responsabilidade fiscal, entre outras coisas (Brasil, 2000).

Apesar do aumento de investimento nas redes, a infraestrutura hospitalar do país continuou deficitária em face das necessidades da população. Devido às restrições atuais, a assistência médico-hospitalar apresenta-se como crítica para o sistema. Torna-se comum a divulgação diária de notícias acerca das condições precárias presentes nos hospitais do SUS, especialmente com o aumento da incidência de agravos específicos como doenças cardiovasculares e traumas. Nesse contexto, a emergência de PPP em saúde como alternativa viável de investimentos no setor apresenta-se como uma das possibilidades de resolução dos déficits estruturais do sistema.

O desenvolvimento de reformas institucionais pelo governo Thatcher no Reino Unido, nos anos 1980, com a revisão dos papéis do Estado e da iniciativa privada, propiciou a emergência de ações que reduziram atribuições, transformaram e flexibilizaram a gestão por meio do New Public Management (Peci e Sobral, 2007). A PPP surge em 1992, composta por um rol de ações envolvendo capital privado nos investimentos em infraestrutura, especialmente em obras e gestão de serviços públicos. Dentre as justificativas apresentadas para a utilização do modelo são citados: a melhoria na disponibilidade de serviços públicos, o compartilhamento de riscos, a maior eficiência do setor privado na gestão, o aumento da eficiência orçamentária do Estado, a melhoria na governança e o aumento dos investimentos em serviços públicos (Grilo, 2008).

No Reino Unido o conceito de PPP envolve diversas abordagens das relações entre Estado e iniciativa privada, incluindo-se: o controle privado de empresas estatais; o Private Finance Initiative (PFI), em que o poder público contrata a compra de serviços no longo prazo; a venda de serviços públicos em mercados abertos; e outros modelos em que a capacidade financeira privada é utilizada para exploração comercial dos ativos do governo (Sundfeld, 2005). O PFI britânico implica arranjos estruturados de contratação entre poder público e entes privados para o desenvolvimento de projetos que se equivalem às concessões comuns e às concessões de PPP brasileiras.

A utilização das PPPs como mecanismo de financiamento da renovação de infraestrutura de saúde teve no Reino Unido forte incremento nas décadas subsequentes à implantação dos PFI. Até 1997, de um volume de 47 estudos submetidos ao governo britânico, inexistiam projetos relativos a estruturas de saúde. Em 2003, 16\% dos projetos existentes no HM Treasury se destinavam ao setor, entre hospitais, unidades de atenção primária e serviços de apoio clínico. Estima-se que até 2010 ocorreram 277 projetos de construção e implantação de serviços assistenciais em saúde representando investimentos superiores a $£ 20$ bilhões (Brasil, 2011).

Em Portugal, o programa de parcerias foi instituído em 2002 com a regulamentação de modelos de investimento e gestão de unidades hospitalares. Imprecisão na administração de riscos, impactos orçamentários imprevistos, atrasos nos cronogramas dos projetos compuseram a maioria dos problemas enfrentados pela iniciativa (Monteiro, 2005). Além disto, ela abrangia originalmente tanto instalação e manutenção de infraestrutura quanto a prestação 
de serviços clínicos, o que gerava nos parceiros privados insegurança diante das incertezas dos projetos (Melo e Campos, 2009). Uma das soluções encaminhadas foi o desenvolvimento de dois tipos de contrato: com ou sem inclusão da gestão clínica.

A Espanha, a partir de 2006, implantou dois modelos de PPP em saúde, caracterizados pela concessão de obras ou de serviços públicos. No primeiro, o poder público é proprietário dos ativos e gerencia diretamente os serviços de saúde, cabendo à iniciativa privada a gestão dos serviços de manutenção e apoio administrativo, remunerados por contraprestação. No segundo os ativos são de propriedade pública, mas os serviços clínicos também fazem parte da contratualização, sendo o parceiro privado remunerado per capita, com base na população adscrita. Entre os principais exemplos de utilização do modelo que inclui os serviços clínicos estão as regiões administrativas de Valência, onde cinco novos hospitais atendem 948 mil habitantes, e de Madri, cuja população de 1,7 milhão vem sendo atendida por oito novos hospitais, integrados por sistema de registro eletrônico, central diagnóstica e base laboratorial comuns. Esse programa envolveu, no país, em 2011, a cobertura de 6 milhões de usuários em 32 hospitais, 420 unidades básicas, 33 centros ambulatoriais, um sistema de atendimento às urgências e emergências, garantiu emprego para mais de 80 mil profissionais de saúde e alocou recursos da ordem de $€ 1,7$ bilhão (GV-Saúde, 2012).

No Chile, a implantação de hospitais construídos e operados pela iniciativa privada começou a ser estruturada durante o governo Ricardo Lagos em consequência do sucesso do modelo na construção e manutenção de estradas (Bachelet, 2014). Foram desenvolvidos os projetos dos hospitais de El Salvador de Santiago, Antofogasta e Félix Bulnes e estabelecidos parâmetros de avaliação que implicaram o reposicionamento dos governos Bachelet e Piñera em virtude de questionamentos da Controladoria-Geral da República e da inexperiência com a nova modalidade de concessão no país. Entre os argumentos relevantes citados pela autora que fundamentariam a proposição de concessões de serviços públicos sociais e de saúde estava a relativa capacidade de reduzir rapidamente a "brecha sanitária", a não geração de dívida fiscal imediata, a introdução de suposta melhoria gerencial das estruturas, a liberação de parte de capacidade de investimento do Estado em outras políticas sociais, a agilidade nos procedimentos de compras do setor privado e a manutenção do princípio de subsidiariedade do Estado.

Davies (2010) e Pollock e colaboradores (2011) apud Bachellet (2014) detalham em sua revisão as potenciais dificuldades que têm acometido os sistemas mais antigos e mais experientes em relação aos projetos de PFI, o inglês e o canadense, e se referem à imprevisibilidade sobre a evolução de desencaixes financeiros de longo prazo, à garantia de equidade do acesso, à insuficiente capacidade de cobertura de rede assistencial dos projetos, à não consecução de padrões de qualidade de assistência compatíveis com as necessidades da população e o comprometimento fiscal de gerações futuras. Bachelet (2014) ainda salienta o esforço pela manutenção de condições que permitam a comparação entre a assistência provida diretamente pelo Estado ou pela iniciativa privada como elemento-chave da continuidade dos programas. 
No Brasil a concepção de PPP envolve o estabelecimento de relação contratual entre poder público e parceiro privado num âmbito diferente daquele utilizado nos contratos administrativos previstos pela Lei no 8.666 (Brasil, 1993) e são identificados dois mecanismos principais de formalização:

v O contrato de gestão estabelecido entre o Estado e as Organizações Sociais (OS) (Lei $\mathrm{n}^{\circ}$ 9.637/1998) ou Organizações da Sociedade Civil de Interesse Público (OSCIP) (Lei no 9.790/1999), nas áreas de educação, saúde e cultura, com pactuação de metas físicas e de qualidade, e com controle pela sociedade civil em seus conselhos de administração. São exemplos desse modelo as contratualizações de hospitais e serviços públicos com organizações filantrópicas e/ou de ensino superior em saúde sem fins lucrativos (Wanderley et al., 2012). Tem como características importantes a limitação de contratação a entidades sem fins lucrativos e requisitos de qualificação determinados por decretos específicos.

Estes contratos enfrentam no espaço dialógico do setor a concorrência entre defensores e detratores do modelo. Estes consideram que saúde constitui atividade indelegável à iniciativa privada, enquanto aqueles defendem uma flexibilização que permita ganhos de eficiência que beneficiem usuários finais.

- O desenvolvimento de uma relação contratual com a instituição de dois modelos de concessão que se diferenciam da concessão tradicional pelo aporte complementar de recursos do governo no custeio de atividades de prestação de serviços tarifados (concessão patrocinada) e pelo custeio integral dos serviços prestados pelo parceiro privado aos usuários finais (concessão administrativa) (Brasil, 2004).

Essa lei, que instituiu nacionalmente o conceito de PPP, estabelece uma série de requisitos a serem atendidos. Entre os principais citam-se: o estudo sobre conveniência e oportunidade da utilização do modelo, análise de necessidades, comparação com alternativas de contratação e justificativa da opção. A PPP se processa com base em estudos técnicos, estimativa da demanda, projetos técnico-operacionais, estabelecimento de indicadores de níveis de desempenho (Service Level Agreement - SLA); estudos de viabilidade econômico-financeira, modelos jurídicos e de negócio, compartilhamento de benefícios e riscos entre os parceiros; consulta pública do projeto por ao menos 30 dias e realização de processo licitatório baseado em critérios de habilitação técnica e de preço (Portugal e Prado, 2007; Sundfeld, 2014). No entanto, a aplicação do modelo contratual implica o desenvolvimento de plataforma de avaliação do Value for Money (VFM) que valida a conveniência e a oportunidade da realização do empreendimento (Portugal e Prado, 2007; Carrera, 2014).

A complexidade dos projetos pode demandar dos parceiros privados formuladores do procedimento de manifestação de interesse (PMI) o apoio de várias áreas de conhecimento. Avaliação de perfis epidemiológicos e demográficos, desenvolvimento de projetos básicos de arquitetura e de tecnologia, dimensionamento de necessidades de recursos de investimentos e de possíveis agentes financiadores e organização jurídica de consórcio e das sociedades de propósito específico (SPE) são demandas correntes na estruturação de projetos em saúde. 
Dado o grau de complexidade que abrange o tema e as possíveis assimetrias de informação e análise que envolvem os parceiros, a proposição de unidades de saúde por meio de PPP não deve prescindir de uma criteriosa avaliação da pertinência de sua implantação e das matrizes de risco e de responsabilidades dos atores envolvidos (Carrera, 2014).

A lei brasileira institui também uma série de estruturas e procedimentos com vistas a garantir um ambiente político e econômico transparente e regulado. Entre eles está a instalação do Comitê Gestor da Parceria Público-Privada (CGP) com as atribuições de selecionar prioridades, promover chamamentos e avaliação dos PMI, aprovar editais, estabelecer contratos e processos licitatórios, e também a criação de fundos garantidores das PPPs (FGP) com o propósito de assegurar aos parceiros privados a regularidade das contraprestações e obrigações pecuniárias assumidas. Esses fundos têm natureza privada e patrimônio próprio, formado pelos valores, bens e direitos integralizados pelos quotistas, no caso os parceiros públicos (Brasil, 2004).

Em termos práticos, o processo de implementação de uma PPP no setor saúde do Brasil envolve idealmente os seguintes passos:

Figura 1

Ciclo de procedimentos necessários ao desenvolvimento e contração de PPP

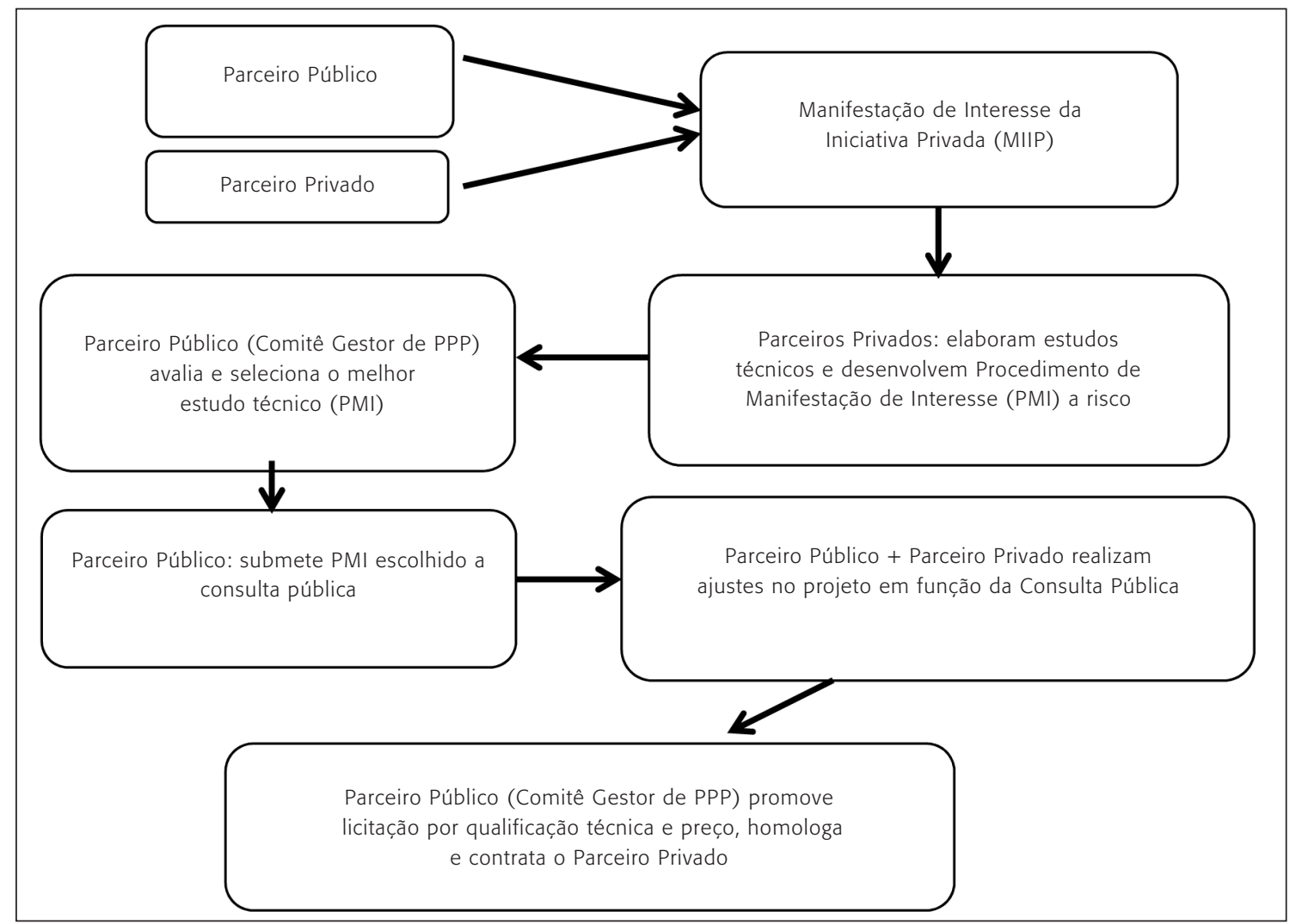

Fonte: Elaborada pelos autores.

Rev. Adm. Pública - Rio de Janeiro 49(5):1143-1165, set./out. 2015 
Alguns aspectos importantes devem ser considerados na proposição e seleção de projetos de PPP em saúde. De acordo com Riess (2005) apud Grilo (2008), o modelo pode ser aplicado em setores em que os serviços possam ser definidos, medidos e avaliados, o que não ocorre em termos práticos nos hospitais. Nesse caso, ambos os parceiros enfrentam dificuldades na definição do que estes autores chamam de projeto de referência para hospitais, posto que o setor ainda se caracteriza por grau elevado de imprevisibilidade e variabilidade de processos. Em consequência torna-se comum na definição de papéis, responsabilidades e compartilhamento de riscos a separação nos projetos das atividades de apoio das propriamente assistenciais.

\section{Método}

Este estudo possui caráter qualitativo e fez uso dos paradigmas tradicionais de falseacionismo e falseabilidade, típicos das ciências sociais (Popper, 1993). Em termos práticos, utilizou-se a tríade tese-antítese-síntese para construir a análise crítica, o que permeia o artigo.

Inicialmente foram usadas as teorias apresentadas no referencial teórico para a elaboração das hipóteses no que se refere ao (bom) funcionamento das parcerias público-privadas no setor de saúde. Três hipóteses básicas foram levantadas, a saber, i) o bom funcionamento da parceria não foi possível por dificuldades com o parceiro público; ii) o bom funcionamento da parceria não foi possível por dificuldades com o parceiro privado; iii) existiram dificuldades estruturais (legais, formativas ou sociais) que impediram o funcionamento adequado da parceria. Note-se que as hipóteses não são mutuamente exclusivas, ou seja, é possível que um caso específico se enquadre em mais de uma hipótese.

As dimensões centrais da análise de cada um dos processos instalados se relacionaram diretamente ao atendimento dos requisitos técnicos da lei reguladora (Brasil, 2004) no que diz respeito ao atendimento das justificativas para os projetos, ao cumprimento das etapas legais, à existência (ou não) de estudo comparativo com a utilização do mecanismo comum de licitações e contratações e compras da Lei no 8.666 (Brasil, 1993), e à constituição do comitê gestor de PPP e do fundo garantidor (FGP) (Brasil, 2004). De forma similar, buscouse identificar, no estudo específico dos projetos estruturados, a demonstração, nos casos em que estes se originaram de PMI da iniciativa privada, do Value for Money (VFM), conforme descrito por Grilo (2008) e Carrera (2012, 2014), e a participação de representantes do setor saúde na análise do mérito dos projetos (Cintra, 2014). Além disso, constituiu dimensão relevante a identificação de elementos que demonstrassem o respeito ao contraditório na evolução dos projetos e se estes foram efetivamente acompanhados no decorrer dos processos de contratação e se constituíram em eventos definidores dos estágios e das causas pelas quais aconteceram interrupções (Sundfeld, 2014). Tal abordagem se justificava em virtude dos questionamentos citados por Bachelet (2014) quanto à efetividade da obtenção de re- 
sultados compatíveis com os discursos que justificaram a maioria dos projetos implantados nos sistemas canadense e britânico e constituíam preocupação das autoridades sanitárias tanto no Chile quanto no Brasil.

Em termos práticos, foram feitos levantamentos bibliográfico e documental. A bibliografia utilizada incluiu não somente publicações acadêmicas, mas também muitas vezes publicações de mídia (<www.pppbrasil.com.br/portal >) que abordaram o tema e tornaram públicas informações sobre as parcerias. Quanto ao levantamento documental, utilizaram-se sempre como ponto de partida as publicações de diários oficiais, ainda que, mais consistentemente, tenham sido os relatórios e as atas de reuniões de comitês gestores que proveram informações com substância para a análise ante as três hipóteses levantadas.

O esforço crítico na tentativa de testar cada uma das hipóteses nem sempre gerou respostas claras e bem definidas, haja vista o percentual significativo das PPPs em saúde no Brasil que se encontra em "áreas cinzentas", em que até mesmo a definição do locus das dificuldades é passível de discussão. Ainda assim, este estudo assumiu uma posição neutra, na medida em que tentou apontar e analisar os possíveis gargalos e constrangimentos que envolvem essa forma relativamente nova de contratação.

\section{Resultados}

A partir da experiência na Bahia o setor privado passou a se interessar por projetos relacionados à saúde, especialmente em hospitais, centros de apoio e logística e centrais de diagnóstico por imagem. Entre janeiro de 2010 e março de 2014 foram estudadas ou propostas ao poder público 24 PPPs abrangendo a construção e instalação de 26 novos hospitais, 184 novas unidades básicas de saúde (UBS), quatro centrais de imagens digitais, cinco centros de apoio operacional e uma fábrica de medicamentos genéricos, além de inúmeros projetos de ampliação e reformas. As iniciativas ocorreram nos estados de São Paulo, Bahia, Rio de Janeiro, Ceará, Mato Grosso, Espírito Santo, Rio Grande do Norte, Rondônia e no Distrito Federal. No âmbito municipal foram estudados projetos em Belo Horizonte, São Paulo, Sorocaba e Manaus. Os projetos partiram tanto de iniciativa do poder público quanto por parte do setor privado, por meio do procedimento de manifestação de interesse.

Deste total identificaram-se projetos envolvendo 36 hospitais, 328 UBS (entre novas e ampliações), quatro centrais de diagnósticos por imagens, quatro centros de apoio logístico e uma indústria farmacêutica em diversas etapas do processo de proposição/ contratação.

O quadro 1 exibe os dados acerca dos 24 projetos em estados e municípios onde foram apresentados, bem como as informações acerca de investimentos previstos, anos em que foram iniciados os procedimentos de estruturação e situações funcionais de cada um deles. 


\begin{tabular}{|c|c|c|c|c|}
\hline Municípios & Projetos & $\begin{array}{l}\text { Investimentos R\$ } \\
\text { milhões }\end{array}$ & $\begin{array}{l}\text { Chamada } \\
\text { Pública e PMI }\end{array}$ & Situação em abr. 2014 \\
\hline \multirow{3}{*}{ BAHIA } & Hosp. Subúrbio & 80 & 2009 & Início de operação 2010 \\
\hline & Inst. Couto Maia & 95 & 2011 & $\begin{array}{l}\text { Licitado 2013. Em } \\
\text { implantação }\end{array}$ \\
\hline & $\begin{array}{l}\text { Central de Diagnóstico por } \\
\text { Imagem }\end{array}$ & 134 & 2012 & Licitado 2013 \\
\hline \multirow{4}{*}{ RIO DE JANEIRO } & 9 Novos Hospitais do Estado & 900 & 2011 & $\begin{array}{l}\text { Processo interrompido na } \\
\text { consulta pública }\end{array}$ \\
\hline & $\begin{array}{l}\text { Central de Diagnóstico RIO } \\
\text { Imagem }\end{array}$ & - & 2011 & $\begin{array}{l}\text { Processo suspenso para } \\
\text { revisão }\end{array}$ \\
\hline & RJ-Plataforma digital em saúde & - & 2013 & Aguarda consulta pública \\
\hline & $\begin{array}{l}\text { Centro de Pesquisas e } \\
\text { Inovação }\end{array}$ & - & 2012 & Aguarda consulta pública \\
\hline \multirow{3}{*}{ SÃO PAULO } & $\begin{array}{l}\text { Hospitais Regionais de } \\
\text { Sorocaba, São José dos } \\
\text { Campos, Inst. da Mulher } \\
\text { e Certoo - Centro de } \\
\text { Referência Oftalmo/ORL }\end{array}$ & 894 & 2012 & $\begin{array}{l}\text { Licitação excluiu Certoo após } \\
\text { consulta pública. Demais } \\
\text { licitados e contratados abr. } \\
2014\end{array}$ \\
\hline & $\begin{array}{l}\text { Ind. Farmacêutica para } \\
\text { Medicamentos de Atenção } \\
\text { Básica }\end{array}$ & 130 & 2011 & $\begin{array}{l}\text { Licitado 2013. Em } \\
\text { implantação }\end{array}$ \\
\hline & $\begin{array}{l}\text { Centrais de distribuição } \\
\text { logísticas das Regiões de Saúde }\end{array}$ & 150 & 2013 & Aguarda consulta pública \\
\hline MATO GROSSO & Hospital Matern. Infantil & 183 & 2012 & $\begin{array}{l}\text { Processo interrompido por } \\
\text { não constituição FGP }\end{array}$ \\
\hline ESPÍRITO SANTO & Hospital Infantil Vitória & 182 & 2012 & Aguarda licitação \\
\hline CEARÁ & Hospital Metropolitano & 253 & 2013 & Licitado abr. 2014 \\
\hline RONDÔNIA & Hospital de Urgência & 100 & 2013 & Aguarda licitação \\
\hline \multirow{4}{*}{$\begin{array}{l}\text { GOVERNO DO } \\
\text { DISTRITO FEDERAL }\end{array}$} & $\begin{array}{l}\text { Hospital de Trauma do DF e } \\
\text { Hospital Novo Gama }\end{array}$ & 734 & 2013 & $\begin{array}{l}\text { Processo suspenso pelo TC/ } \\
\text { GDF }\end{array}$ \\
\hline & $\begin{array}{l}\text { Central de Diagnósticos por } \\
\text { Imagens }\end{array}$ & 51 & 2012 & $\begin{array}{l}\text { Processo suspenso pelo TC/ } \\
\text { GDF }\end{array}$ \\
\hline & $\begin{array}{l}\text { Centro de Apoio Operacional } \\
\text { à Rede hospitalar do GDF }\end{array}$ & - & 2012 & $\begin{array}{l}\text { Processo suspenso pelo TC/ } \\
\text { GDF }\end{array}$ \\
\hline & $\begin{array}{l}\text { Centro Médico da Polícia } \\
\text { Militar }\end{array}$ & - & 2014 & $\begin{array}{l}\text { Realizado chamamento por } \\
\text { MIIP }\end{array}$ \\
\hline
\end{tabular}

Continua 


\begin{tabular}{|c|c|c|c|c|}
\hline Municípios & Projetos & $\begin{array}{l}\text { Investimentos R\$ } \\
\text { milhões }\end{array}$ & $\begin{array}{l}\text { Chamada } \\
\text { Pública e PMI }\end{array}$ & Situação em abr. 2014 \\
\hline \multirow{2}{*}{ BELO HORIZONTE } & Hospital do Barreiro & 180 & 2011 & $\begin{array}{l}\text { Licitado 2012. Em } \\
\text { construção }\end{array}$ \\
\hline & $\begin{array}{l}\text { Sistema de Apoio Operacional } \\
\text { - Rede Básica de Saúde }\end{array}$ & 200 & 2010 & $\begin{array}{l}\text { Licitado 2012. Em } \\
\text { construção }\end{array}$ \\
\hline \multirow[t]{2}{*}{ MANAUS } & Rede Básica de Saúde & 59 & 2012 & $\begin{array}{l}\text { Licitado } 2012 . \\
\text { Contrato suspenso por } \\
\text { incompatibilidade do projeto } \\
\text { executivo }\end{array}$ \\
\hline & Centro de Apoio Operacional & - & 2014 & $\begin{array}{l}\text { Realizado chamamento por } \\
\text { MIIP }\end{array}$ \\
\hline SOROCABA & Hospital Municipal & 140 & 2014 & $\begin{array}{l}\text { Suspenso por coincidência } \\
\text { de escopo com projeto } \\
\text { estadual. Retomado } \\
\text { chamamento com novo } \\
\text { escopo }\end{array}$ \\
\hline SÃO PAULO & $\begin{array}{l}\text { Reforma } 9 \text { hospitais e } \\
\text { construção } 3 \text { novos }\end{array}$ & 1300 & 2011 & $\begin{array}{l}\text { Processo suspenso por } \\
\text { medida judicial. Em fase } \\
\text { de redimensionamento e } \\
\text { ajustes }\end{array}$ \\
\hline
\end{tabular}

Fonte: PPPBrasil (2014). Elaborada pelos autores.

De acordo com Portugal e Prado (2007), a implantação de programas de PPP demanda a elaboração de estudos técnicos, projeções de demanda de serviços, projetos técnicos e econômico-financeiros que permitam aos gestores públicos a comparação com outras formas de investimentos nos setores. Pressupõe também, segundo Sundfeld (2014), a elaboração de modelos de negócios e análises de riscos que permitam seu desenlace em contratos juridicamente adequados, sob controle e conhecimento da sociedade, elaboração de editais e procedimentos licitatórios que atendam aos interesses do poder público e busquem conciliar os interesses dos parceiros privados e da sociedade. Com base na argumentação desses autores, procedeu-se à classificação do estágio em que cada um dos processos se encontrava buscando a classificação das propostas em quatro conjuntos com situações semelhantes, a saber: grupo I — unidades contratadas e implantadas ou em implantação; grupo II — unidades em consulta pública; grupo III - unidades em fase licitatória; e grupo IV — unidades e projetos suspensos por restrições técnicas ou jurídicas.

Do grupo I, apresentado no quadro 2, uma unidade hospitalar estava em funcionamento, três outras em construção, uma rede básica de assistência em implantação e outra teve seu contrato suspenso. Além desses, um centro diagnóstico e uma indústria farmacêutica foram licitados e contratados. Representavam investimentos de R \$ 878 milhões, com implantação de 892 leitos, 318 UBS (160 suspensas) e estruturas de apoio diagnóstico e produção de medicamentos. Do ponto de vista operacional (Brasil, 2004), essas unidades foram consideradas aptas a serem 
contratadas, posto que, além de cumprirem os requisitos legais, tiveram seus procedimentos de análise de mérito validados, corroborando os elementos citados por Cintra (2014) acerca de qualificação e respeito aos interesses da sociedade. Uma PPP (Manaus) foi suspensa por inadequação dos projetos executivos em face do projeto apresentado à consulta pública.

Quadro 2

Grupo I - Hospitais e unidades de saúde contratados após processo licitatório

\begin{tabular}{|lll|}
\hline & \multicolumn{1}{c}{ Situação em 3/2014 } & Prazo de concessão \\
\hline Hosp. Subúrbio BA & Em operação & 10 anos renováveis \\
Inst. Couto Maya BA & Em construção & 20 anos \\
BH Hosp. Barreiro & Em construção & 20 anos \\
BH Sist. Apoio operacional rede básica & Em construção e implantação & 20 anos \\
Manaus Rede básica de saúde & Contrato suspenso pelo parceiro público & 9 anos \\
BAHIA Central diagnóstico por imagem & Em construção e implantação & 15 anos renováveis \\
SP Centro de produção de medicamentos. Atenção básica & Em construção e implantação & 15 anos \\
\hline
\end{tabular}

Fonte: PPPBrasil (2014). Elaborada pelos autores.

O quadro 3 apresenta o grupo II, composto por 3 hospitais totalizando 525 leitos e três unidades de apoio técnico-administrativo em saúde. Os hospitais compreendem um período de concessão de 25 anos, o centro logístico, de 20 anos, e a avaliação documental das outras duas outras unidades não permitiu a identificação desse dado. Do ponto de vista de fluxos e atendimento de requisitos (Cintra, 2014), essas unidades tiveram seus projetos técnicos aprovados pelos CGP e encontravam-se aguardando o conhecimento ou discussão pela sociedade por meio dos procedimentos de consultas públicas.

Quadro 3

Grupo II - Hospitais e unidades de apoio em saúde em fase de consulta pública

\begin{tabular}{|lll|}
\hline & \multicolumn{1}{c|}{ Situação em 3/2014 } & Prazo da concessão \\
\hline Hosp. Urg. Rondônia & Em consulta pública & 25 anos \\
Hosp. Trauma de Natal & Em consulta pública & 25 anos \\
Hosp. Infantil Vitória & Em consulta pública & 25 anos \\
RJ Plataforma digital em saúde & Aguarda consulta pública & Não estabelecido \\
SP Estado. Central de distr. logística & Aguarda consulta pública & 20 anos \\
RJ Centro de pesquisa em inovação em saúde & Aguarda consulta pública & Não estabelecido \\
\hline
\end{tabular}

Fonte: PPPBrasil (2014). Elaborada pelos autores. 
O quadro 4 apresenta os projetos de seis hospitais aqui classificados no grupo III, com projeção de investimentos de $\mathrm{R} \$ 1.449$ milhão, representando a agregação de 1.325 leitos e os prazos previstos de concessão de 25 anos. Esses projetos já haviam cumprido as etapas de avaliação e ajustes em projetos e submissão à consulta pública, passando à etapa de procedimentos licitatórios, tendo cumprido os requisitos legais (Brasil, 2004). Entretanto, por questões de atendimento aos requisitos do processo licitatório (Brasil, 1993), ainda não haviam sido contratados.

Quadro 4

Grupo III - Hospitais em procedimento técnico licitatório ou aguardando liberação de edital de licitação

\begin{tabular}{|llc|}
\hline & Situação em 3/2014 & Prazo da concessão \\
\hline Hosp. Metrop. Ceará & Início licitação: 3/2014 & 25 anos \\
Hosp. Est. Sorocaba SP. & Início licitação: 3/2014 & 25 anos \\
Hosp. Emerg. S. J. Campos & Início licitação: 3/2014 & 25 anos \\
Inst. da Mulher SP & Início licitação: 3/2014 & 25 anos \\
Hosp. Trauma de Natal & Aguarda edital de licitação & 25 anos \\
Hosp. Infantil Vitória & Aguarda edital de licitação & 25 anos \\
\hline
\end{tabular}

Fonte: PPPBrasil (2014). Elaborada pelos autores.

Finalmente, o quadro 5 apresenta oito novos hospitais, nove reformas em hospitais, duas centrais de diagnóstico por imagem e um centro de apoio operacional que compõem o grupo IV. Desse grupo, o primeiro hospital especializado (Certoo) foi excluído após consulta pública que envolvia quatro hospitais no estado de São Paulo. Os hospitais do Distrito Federal, além de sua central de imagens e outra de apoio operacional, foram suspensos pelo comitê gestor do GDF, em virtude de questionamentos levantados pelo Tribunal de Contas Distrital. O processo envolvendo a implantação do centro de diagnósticos por imagem do Rio de Janeiro foi suspenso passando a fazer parte de um projeto mais abrangente que envolve outras funcionalidades dos registros eletrônicos de saúde do estado. O projeto do estado do Mato Grosso não avançou em virtude da não composição de ativos para o fundo garantidor. A proposta de reforma/ampliação de nove hospitais e construção de outros três para o município de São Paulo foi suspensa por determinação do Tribunal de Contas do Município. Em Sorocaba, em face da criação de um novo centro hospitalar estadual para atenção ao trauma e urgências, a Secretaria de Saúde decidiu rever o escopo e as datas de lançamento da MIIP. Entre as causas observadas neste grupo foi possível identificar duas vertentes importantes; a primeira relacionada à dificuldade de cumprimento dos requisitos legais com a exclusão de um projeto por ausência de justificativa econômica e outro por inexistirem garantias de longo prazo (Brasil, 
2004), e a segunda relacionada aos questionamentos de pertinência e adequação do modelo conforme descrito por Bachelet (2014).

Quadro 5

Grupo IV - Hospitais e unidades de apoio com restrições jurídicas e técnicas

\begin{tabular}{|c|c|c|}
\hline & Situação em 3/2014 & Origem da objeção \\
\hline Certoo - Ref. Oftalmo/ORL & Excluído do edital pós-consulta pública & Ausência de justificativa econômica \\
\hline Hosp. Mat. Infantil de Mato Grosso & Interrompido pós-consulta pública & Não constituição do Fundo Garantidor \\
\hline Hosp. Novo Gama - GDF & Suspenso pós-intervenção do TC/GDF & $\begin{array}{l}\text { Questionamento TC sobre cumprimento } \\
\text { de dispositivos legais }\end{array}$ \\
\hline Hosp. Trauma - GDF & Suspenso pós-intervenção do TC/GDF & $\begin{array}{l}\text { Questionamento TC sobre cumprimento } \\
\text { de dispositivos legais }\end{array}$ \\
\hline S. PAULO (9 reformas + 3 novos) & $\begin{array}{l}\text { Processo suspenso pelo TCM. Em fase de } \\
\text { planejamento de novo redimensionamento }\end{array}$ & $\begin{array}{l}\text { Questionamento TCM sobre extensão } \\
\text { do projeto }\end{array}$ \\
\hline GDF Centro Diagnóstico por Imagem & Suspenso pós-intervenção do TC/GDF & $\begin{array}{l}\text { Questionamento TC sobre cumprimento } \\
\text { de dispositivos legais }\end{array}$ \\
\hline
\end{tabular}

Fonte: PPPBrasil (2014). Elaborada pelos autores.

\section{Discussão e conclusões}

A análise da evolução dos procedimentos elencados no ciclo técnico para cada um dos processos permitiu a identificação do estágio em que se encontravam os projetos propostos. Além disso, a identificação dos casos que apresentaram efetividade na conclusão de seus processos, assumindo como premissa a contratação entre os parceiros público e privado e corroborando o modelo descrito por Portugal e Prado (2007) e Sundfeld (2014). Considerou-se como situação de sucesso a contratação realizada entre as secretarias de saúde dos estados da Bahia (Hospital do Subúrbio, Instituto Couto Maya e Central de Imagens Digitais), São Paulo (planta de produção farmacêutica), e dos municípios de Belo Horizonte (Hospital do Barreiro e rede de apoio operacional a rede básica) e Manaus (Implantação da rede básica), cujos projetos tiveram suas implantações iniciadas.

Em relação a esses projetos, o que se observou foi que atenderam a todos os requisitos legais, cumprindo as exigências sob responsabilidade de cada um dos parceiros, a saber:

v parceiro privado: desenvolvimento do projeto técnico baseado em informações epidemiológicas, desenhos de plantas operativas e do rol de equipamentos/tecnologias médicas, elaboração de plano de negócios e modelagem jurídica, matrizes de riscos e responsabilidades (Carrera, 2014). 
จ parceiro público: instituição de comitê gestor com a participação do setor saúde, desenvolvimento do fundo garantidor, avaliação dos projetos apresentados por meio dos PMI com seleção do mais adequado às necessidades, divulgação do projeto, submissão a audiências e consultas públicas, elaboração e execução do processo licitatório, homologação e implantação dos contratos (Brasil, 2004; Sundfeld, 2005, 2014).

Cabem observações adicionais em relação a esses processos: a) não ficou evidenciada a existência de mecanismos de verificação independente em todos os projetos do grupo prevista na lei instituidora (Brasil, 2004), atribuição prevista no processo, mas ainda carente de melhor definição; b) os indicadores de desempenho a serem monitorados pelo parceiro público não estavam presentes em todos os contratos e anexos submetidos às consultas públicas, o que não cria segurança jurídica nem condições adequadas de supervisão contratual e consequente imposição de penalidades pecuniárias pelo seu descumprimento. Tais eventualidades constituem parte das razões alegadas por Bachelet (2014) pela perda de confiança no modelo presente nas PPPs no Reino Unido e Canadá; c) nos hospitais estudados predominou a contratação de atividades de apoio técnico-administrativo como responsabilidade do parceiro privado, existindo uma única experiência em que este aspecto inclui também a atividade assistencial, dicotomia já apontada nas experiências de Portugal (Melo e Campos, 2009) e Espanha (GV-Saúde, 2012); d) por incompatibilidade entre projeto e execução do contrato pelo parceiro privado, a prefeitura de Manaus suspendeu a contratação. Por insuficiência de informação acerca das causas do ocorrido no projeto, entre as quais razões do poder concedente para a suspensão, este constitui caso para melhor estudo, tendo em vista o ambiente de instabilidade e desconfiança passível de influenciar outros projetos (Carrera, 2014; Cintra, 2014).

Em relação aos projetos do grupo II, em fase de ou aguardando consulta pública, observou-se que o tempo decorrido entre as apresentações dos projetos e sua submissão teve atrasos e reagendamentos por solicitação dos dois parceiros. Razões técnicas relacionadas ao escopo e à dimensão dos projetos, bases de conhecimentos para elaboração de justificativas de oportunidade e pertinência, e garantias contratuais estão entre as mais importantes do ponto de vista dos parceiros privados. Por parte do poder concedente, as preocupações mais evidentes referem-se: ao impacto orçamentário de longo prazo e consequente capacidade do Estado em cumprir a Lei de Responsabilidade Fiscal; à inexperiência ou insuficiência de conhecimentos acerca dos modelos e de como avaliá-los com isenção e transparência; à constituição dos fundos garantidores e à agenda política regional. Além disso, em determinadas situações ocorre nas sociedades locais uma discussão ideológica acerca dos modelos e do quanto tais empreendimentos promovem desequilíbrios sobre o direito dos cidadãos e alteram as condições de trabalho do setor. Essas discussões, na maioria das observações, partem de questionamentos dos conselhos de saúde e dos sindicatos de trabalhadores em saúde. Essas observações vêm de encontro aos argumentos apresentados por Portugal e Prado (2007) quanto às necessidades de estudos técnicos que embasem as proposições, e de Cintra (2014), que refere a insegurança preponderante entre os dois parceiros em que am- 
bos acreditam na deslealdade pela outra parte, levando à criação de inúmeros e complexos instrumentos de defesa bilateral, constituindo esse aspecto em entrave para a consolidação de PPP no Brasil.

No grupo III, as mesmas observações colocadas em relação ao grupo II constituíram parte das observações mais frequentes. Entretanto, vencida a etapa de consulta à sociedade, os projetos poderiam ser levados ao certame licitatório, o que não vem ocorrendo por diversas razões. Por parte do parceiro privado, além das já citadas, destacam-se: a reorganização econômico-financeira em virtude do tempo decorrido entre o desenvolvimento do projeto e a efetiva contratação; a revisão dos indicadores de desempenho propostos em função de dificuldades de estruturação de consórcios que atendam a todas as funcionalidades previstas; o acesso a financiamento subsidiado em bancos de fomento ou a recursos que possam provir de fontes públicas e sua consequente tributação na fase de implantação. Por parte do poder concedente, as principais dificuldades referem-se: aos projetos técnicos e suas especificações; à capacidade de provisão de recursos adicionais de outras fontes, especialmente em relação ao custeio da operação assistencial; à capacidade de pagamento do setor em face de um contrato de longo prazo e ao perfil de serviços atribuíveis ao parceiro privado que, em alguns dos processos estudados, passou por revisões no sentido de redução de escopo sem consequente redução nos valores propostos para a contraprestação. Tais situações corroboram os argumentos relatados por Bachelet (2014) como pontos críticos dos contratos de concessão nas experiências chilena, canadense e britânica e compuseram também os ambientes dos programas de Portugal (Melo e Campos, 2009) e de Espanha (GV-Saúde, 2012).

Uma das questões mais relevantes para ambos é: qual será o modelo de prestação de serviços a ser adotado: se por administração direta ou por meio de contrato de gestão com organizações sem fins lucrativos. Entre os grupos de indicadores de desempenho obtidos e que farão parte do monitoramento independente para a contraprestação, existe um volume razoável de itens que depende estritamente da utilização dos serviços (p.e., tempo médio de permanência, percentual de ocupação, tempo de liberação das unidades para novos procedimentos, número de refeições dispensadas, quantitativo de pacientes atendidos), que são afetados pelo modelo de gestão a ser implantado. A impressão é que os modelos de administração direta dos hospitais têm menos eficiência operacional que aqueles regidos por um contrato de orçamento global com remuneração por metas de desempenho físico e de qualidade. Essa questão se torna pertinente nas etapas de contratação, em decorrência da separação entre as atividades assistenciais (chamada "bata branca") das de apoio, que comporão o escopo dos serviços a serem cumpridos pelo parceiro privado ("bata cinza"). Novamente aqui se apresenta a discussão entre quais as melhores formas de prestação da assistência, se por serviços próprios ou contratados junto a organizações sociais, por demanda dos conselhos de saúde e dos sindicatos das profissões de saúde (Sundfeld, 2014).

O grupo IV, composto por projetos com restrições técnicas, de ordem institucional ou jurídica, apresenta três componentes importantes. O primeiro refere-se a projetos que foram 
propostos ou postergados por questão de escopo. Destes, o projeto do Hospital Infantil de MT foi suspenso por dificuldades de organização do fundo garantidor, o projeto do centro de referência em oftalmologia e otorrinolaringologia foi excluído por critérios de pertinência econômica e o projeto do hospital municipal de Sorocaba para evitar coincidência de escopo e agenda com o hospital regional de urgência e emergência do estado, demonstrando a dificuldade de cumprimento das exigências da Lei no 11.079 (Brasil, 2004). O segundo componente é relacionado aos questionamentos que o Tribunal de Contas do GDF realiza junto às instâncias responsáveis do governo distrital, que levaram o comitê gestor a interromper o processo para revisões de escopo, dimensão e justificativas. O terceiro componente é decorrente de decisão do Tribunal de Contas de São Paulo no sentido de rever o projeto de reforma e ampliação dos hospitais do município.

A percepção sobre as observações apresentadas nos quatro grupos descritos possibilita a inferência de atributos específicos que envolvem os atores do processo. Possivelmente, a extensão relativamente longa dos procedimentos que fundamentam a contratação tem estrita relação com sua abordagem e equacionamento. Entre estes atributos podem ser citados:

v A insegurança que envolve o desenvolvimento do modelo por parte de todos os atores. Entre suas prováveis causas estão a novidade do modelo no país e as limitações de foco jurídico a ele associados, em conformidade com o referido por Cintra (2014) e Sundfeld (2005, 2014).

、 A assimetria de informações que caracteriza a gestão das organizações públicas e privadas. O pressuposto mais comum é que a iniciativa privada dispõe de maior capacidade de processamento e elaboração estratégica que o poder concedente, levando à limitação de confiança entre os parceiros (Carrera, 2014).

、 A insuficiente capacidade de execução de estudos gerenciais em epidemiologia que permitam a modelagem de projetos dentro de bases mais próximas das necessidades da população e dos gestores do SUS, em consonância com o descrito por Carrera (2012). A autora, inclusive, cita o descompasso acompanhado durante a implantação do Hospital do Subúrbio em que a previsão de ocupação das estruturas edificadas foi superada nos três primeiros meses da operação hospitalar, demandando o equacionamento contratual entre as partes e a realização de novos investimentos que garantissem a cobertura assistencial da população de referência da unidade.

、 A preocupação com os fluxos financeiros do Estado e do poder concedente relacionada com sua capacidade de honrar os contratos no longo prazo sem comprometer futuras gerações, questão que envolve posicionamentos políticos e estratégicos de longo prazo (Cintra, 2014; Bachelet, 2014).

v A eliminação do risco de intervenção do poder concedente com a estatização dos empreendimentos contratados. 
、 A indefinição, para os propósitos das parcerias, do modelo de gestão da atenção direta ao paciente, se por administração direta ou por contratos de orçamento global auditáveis por indicadores de desempenho.

、 O questionamento sobre a incorporação ou não de servidores públicos estáveis no modelo dos projetos.

、 O envolvimento das instâncias de controle social previsto na Lei no 8.142 (Brasil, 1990b) na avaliação, auditoria, controle e aprovação das contraprestações.

v A transparência na divulgação do processo e o compromisso político com o modelo.

\section{Considerações finais}

O sistema público de saúde no Brasil se defronta na atualidade com importantes questionamentos acerca de seu modelo. Entre eles, se destacam financiamento, capacidade operacional, estrutura gerencial, qualidade dos serviços prestados, resolubilidade disponível, formas de garantir segurança aos usuários e equidade no acesso aos recursos. Por sua parte, a iniciativa privada apresenta preocupações com relação às possibilidades de investimentos no setor, sua perenidade, o retorno sobre o capital investido, as formas para assegurar juridicamente o cumprimento dos contratos e para contribuir com o desenvolvimento da sociedade no sentido de provisão de serviços.

O desenvolvimento de projetos de PPPs no setor saúde caracteriza-se pela complexidade e pelo envolvimento de múltiplos atores e interesses. Representa também uma oportunidade especial de melhoria da assistência à saúde com investimentos em novas estruturas que venham a suprir as deficiências crônicas do setor, do ponto de vista de disponibilidade de recursos assistenciais. Resolver os entraves destes projetos demanda conhecimento das necessidades e do sistema de saúde, objetivos e interesses do setor privado, interação com agentes públicos e de controle social e uma capacidade de diálogo e comunicação incomuns.

Na resolução dessas questões reside a evolução do programa para uma próxima fase em que a sociedade esteja mais envolvida com o "problema" saúde, com opções claras, estáveis e estimulantes da melhoria das condições de vida de nossa população.

\section{Referências}

BACHELET, Vivienne C. Hospital concessions in Chile: where we are and where we are heading. Medwave, v. 14, n. 10, p. 1-7, nov. 2014.

BARBOSA, Estela C. 25 anos do Sistema Único de Saúde: conquistas e desafios. Revista de Gestão em Sistemas de Saúde, v. 2, n. 2, p. 85-102, jul./dez. 2013. 
BRASIL. Câmara dos Deputados. Consultoria de Orçamento e Fiscalização Financeira. Núcleo de Saúde. 2011a. Disponível em: <www2.camara.leg.br/a-camara/estruturaadm>. Acesso em: 2 abr. 2014.

BRASIL. Constituição da República Federativa do Brasil. Seção II. Artigos 196 a 200. Dispõem sobre a saúde, 1988. Disponível em <www.planalto.gov.br/ccivil_03/constituicao/constituicao.htm>. Acesso em: 1ํabr. 2014.

BRASIL. Lei 8.080. Dispõe sobre as condições para a promoção, proteção e recuperação da saúde, a organização e o funcionamento dos serviços correspondentes e dá outras providências. 1990a. Disponível em: <www.planalto.gov.br/ccivil_03/leis/18080.htm>. Acesso em: 22 mar. 2014.

BRASIL. Lei 8.142. Dispõe sobre a participação da comunidade na gestão do Sistema Único de Saúde (SUS) e sobre as transferências intergovernamentais de recursos financeiros na área da saúde e dá outras providências. 1990b. Disponível em: <www.planalto.gov.br/ccivil_03/leis/18142.htm>. Acesso em: 22 mar. 2014.

BRASIL. Lei 8.666. Regulamenta o artigo 37, inciso XXI da Constituição Federal de 1988, Diário Oficial — República Federativa do Brasil, Poder Executivo, Brasília, DF, 22 jun. 1993.

BRASIL. Lei 11.079. Institui normas gerais para licitação e contratação de parcerias público-privadas no âmbito da administração pública. Diário Oficial — República Federativa do Brasil. Poder Executivo, Brasília, DF, 31 dez. 2004.

BRASIL. Lei Complementar no 101, de 4 de maio de 2000. Estabelece normas de finanças públicas voltadas para a responsabilidade na gestão fiscal e dá outras providências, 2000. Disponível em: <www.planalto.gov.br/ccivil_03/leis/LCP/Lcp101.htm>. Acesso em: 10 abr. 2014.

BRASIL. Ministério da Saúde. Cadastro Nacional de Estabelecimentos de Saúde - CNES, 2012. Indicadores e Dados Básicos — IDB - 2012. Disponível em: < http://tabnet.datasus.gov.br/cgi/ idb2012/matriz.htm>. Acesso em: 25 mar. 2014.

BRASIL. Ministério do Planejamento, Orçamento e Gestão. Cursos. PPP em saúde: Appraisal of Outline business cases, 2011. Disponível em: <www.planejamento.gov.br/hotsites/ppp/conteudo/ cursos/arq_down/saude_segurança >. Acesso em: 2 abr. 2014.

BRASIL. Portaria MS n. 399/2006 de 22 de fevereiro de 2006. Divulga o Pacto pela Saúde 2006 Consolidação do SUS e aprova as Diretrizes Operacionais do Referido Pacto. 2006. Disponível em: <http://bvsms.saude.gov.br/bvs/ publicacoes>. Acesso em: 13 fev. 2009.

CARRERA, Mariana B. M. Parceria público-privada na saúde no Brasil: estudo de caso do Hospital do Subúrbio de Salvador — Bahia. Dissertação (mestrado) — Escola de Administração de Empresas de São Paulo, Fundação Getulio Vargas, São Paulo, 2012.

CARRERA, Mariana B. M. Parceria público-privada (PPP): análise do mérito de projetos do setor saúde no Brasil. Tese (doutorado) — Escola de Administração de Empresas de São Paulo, Fundação Getulio Vargas, São Paulo, 2014. 
CINTRA, Marcos. Modelagem de PPP: pré-requisitos fundamentais e suas implicações. Cadernos FGV Projetos, v. 9, n. 23, p. 44-53, jan. 2014.

DAVIES, Peter. Hard times: is this the end of the road for private finance initiative? BMJ, v. 341, c3828, jul. 2010.

GRILO, Leonardo M. Modelo de análise da qualidade do investimento em projetos de parcerias público -privadas (PPPS). Tese (doutorado) — Escola Politécnica, Universidade de São Paulo, São Paulo, 2008.

GV-SAÚDE. Especial palestra internacional 2011 — PPP na saúde: experiências e tendências, 2012. Disponível em: < http://gvsaude.fgv.br/sites/gvsaude.fgv.br/files/GVsaude\%20FINAL.pdf>. Acesso em: 26 mar. 2014.

HM TREASURY. PFI: strengthening long-term partnerships. Londres: HM Treasury, 2006.

IBGE. Instituto Brasileiro de Geografia e Estatística. Séries estatísticas e séries históricas. 2014. Disponível em: <www.ibge.gov.br/home>. Acesso em: 28 mar. 2014.

MEDICI, André C. Do global ao local: os desafios da saúde no limiar do século XXI. Belo Horizonte: Coopmed, 2011.

MELO, Pedro; CAMPOS, Diogo D. PPPs in the Portuguese health sector. EPPPL: European Public Private Partnership Law Review, v. 4, n. 3, p. 177-178, 2009.

MENDES, Eugenio V. As redes de atenção à saúde: uma mudança na organização e na gestão dos sistemas de atenção à saúde. In: VECINA NETO, Gonzalo; MALIK, Ana M. (Org.). Gestão em saúde. Rio de Janeiro: Guanabara Koogan, 2011. p. 32-49.

MONTEIRO, Riu Souza. Public-private partnerships: some lessons from the Portuguese experience. In: EIB CONFERENCE ON ECONOMICS \& FINANCE, 2005, Luxemburgo. Mimeografado.

PECI, Alketa; SOBRAL, Filipe. Parcerias público-privadas: análise comparativa das experiências inglesa e brasileira. Cadernos Ebape.BR, v. 5, n. 2, p. 1-14, 2007.

POPPER, Karl R. A lógica da pesquisa científica. 5. ed. São Paulo: Cultrix, 1993.

PORTAL CFM. Jornal Medicina. Brasil perde 14,7 mil leitos de internação. nov. 2014. Disponível em: <http://portal .cfm.org.br>. Acesso em: 22 dez. 2014.

PORTUGAL, Mauricio; PRADO, Lucas N. M. Comentários à lei de PPP: parceria público-privada: fundamentos econômico-jurídicos. São Paulo: Malheiros, 2007.

PPPBRASIL. Observatório das parcerias público-privadas. 2014. Disponível em: < http://pppbrasil. com.br/portal>. Acesso em: 25 abr. 2014.

SUNDFELD, Carlos A. O direito e as parcerias empresariais e contratuais entre Estado e particulares. Cadernos FGV Projetos, v. 9, n. 23, p. 54-61, jan. 2014.

SUNDFELD, Carlos A. Parcerias público-privadas. São Paulo: Malheiros, 2005.

WANDERLEY, Karla L. et al. Análise do processo de implantação de políticas na área hospitalar do Ministério da Saúde: contratualização dos hospitais de ensino e filantrópicos no SUS. In: MINIS- 
TÉRIO DA SAÚDE; SOCIEDADE HOSPITAL SAMARITANO (Org.). A política de reestruturação dos hospitais de ensino e filantrópicos no Brasil no período de 2003-2010. Brasília: Ministério da Saúde, 2012. p. 26-89.

Antonio Pires Barbosa, doutor em administração de empresas pela Escola de Administração de Empresas de São Paulo, Fundação Getulio Vargas (Eaesp/FGV) e professor doutor do Mestrado Profissional Gestão em Sistemas de Saúde, Universidade Nove de Julho (SP). E-mail: rbe.pires@gmail.com.

Ana Maria Malik, doutora em medicina pela Faculdade de Medicina da Universidade de São Paulo (FM/ USP) e professora titular da Escola de Administração de Empresas de São Paulo, Fundação Getulio Vargas (Eaesp/FGV). E-mail: Ana.Malik@fgv.br. 